\title{
The impact of pegylated recombinant human growth hormone replacement therapy on glucose and lipid metabolism in children with growth hormone deficiency
}

\author{
Cencen Wang ${ }^{1}$, Heqing Huang ${ }^{2}$, Chen Zhao ${ }^{1}$, Jiao Zhao ${ }^{1}$, Runji Xiong ${ }^{1}$, Runming Jin ${ }^{1}$, Yan Bai ${ }^{1} \wedge$ \\ ${ }^{1}$ Department of Pediatrics, Union Hospital, Tongji Medical College, Huazhong University of Science and Technology, Wuhan, China; ${ }^{2}$ Department \\ of Pediatrics, Uoion and East-west Lake Hospital, Huazhong University of Science and Technology, Wuhan, China \\ Contributions: (I) Conception and design: C Wang, H Huang; (II) Administrative support: C Zhao, Y Bai; (III) Provision of study materials or patients: \\ H Huang; (IV) Collection and assembly of data: J Zhao, Y Bai; (V) Data analysis and interpretation: R Xiong, R Jin; (VI) Manuscript writing: All \\ authors; (VII) Final approval of manuscript: All authors. \\ Correspondence to: Yan Bai, MD, PhD. Department of Pediatrics, Union Hospital, Tongji Medical College, Huazhong University of Science and \\ Technology, No. 1277 of Jiefang Street, Jianghan District, Wuhan 430022, China. Email: Yanbaixh@hust.edu.cn.
}

Background: This study aimed to investigate the impact of pegylated recombinant human growth hormone (PEG-rhGH) replacement therapy on glucose and lipid metabolism in children with growth hormone deficiency (GHD).

Methods: A total of 17 children with a growth hormone deficiency were treated with PEG-rhGH (trade name Juyi' Erchun) via subcutaneous injection once a week before sleep for 3 months. The doses given were 0.2 and $0.15 \mathrm{mg} /(\mathrm{kg} \cdot$ week). The injection sites included the upper arm, the front of the thigh, and the periumbilical area of the abdominal wall. Follow-ups were conducted every 3 months after the treatment to detect the metabolic indexes of the children's blood glucose and blood lipids. Growth and development indexes, thyroid function, and other indexes were also detected regularly. The glucose and lipid metabolism indexes of each child, including fasting blood glucose, glycosylated hemoglobin, fasting insulin, total cholesterol, triglycerides, high-density lipoprotein (HDL), and low-density lipoprotein (LDL), were measured before the treatment and every three months after the treatment. The total detection time was 3-30 months.

Results: No significant differences in fasting blood glucose, glycosylated hemoglobin, fasting insulin, total cholesterol, triglycerides, HDL, and LDL were detected after the treatment when compared with measurements taken before the treatment $(\mathrm{P}>0.05)$.

Conclusions: PEG-rhGH replacement therapy may have no significant impact on glucose and lipid metabolism in children with GHD. However, this conclusion needs to be verified through studies with larger samples and long-term follow-up periods.

Keywords: Growth hormone deficiency; children; pegylated recombinant human growth hormone; blood glucose; blood lipid

Submitted Apr 01, 2020. Accepted for publication Sep 30, 2020.

doi: $10.21037 /$ apm-20-871

View this article at: http://dx.doi.org/10.21037/apm-20-871

^ ORCID: 0000-0001-5039-4093. 


\section{Introduction}

Growth hormone deficiency (GHD), also known as pituitary dwarfism, refers to growth and development disorders caused by the partial or complete lack of growth hormone (GH) synthesized and secreted by the adenohypophysis (anterior pituitary), structural abnormalities, receptor defects, etc. In children, the most common manifestations of the disease include a height below the third percentile, or two standard deviations lower than average, on the growth curve for their age and gender (thereby meeting the short stature standard) (1). The causes of GHD can be divided into two categories: (I) secondary GHD, in which the condition is secondary to other diseases or injuries, such as brain injury, a tumor, or brain surgery, and (II) congenital GHD, which is caused by genetic defects or primary/idiopathic GHD. Even with these causes removed, it is difficult to achieve spontaneous recovery in the state of GHD, so patients need to be supplemented with drugs.

At present, the treatment of GHD includes recombinant human growth hormone (rhGH) replacement therapy $(2,3)$. A short-term GH compliance questionnaire completed by 200 children of short stature demonstrated that 188 had received short-term rhGH treatment and 179 had received rhGH treatment for more than a year. However, only $48.9 \%$ of the children had good compliance (their treatment plans were strictly followed and the number of missed injections between two follow-up visits was between zero and five), while children with discontinuous treatment (the number of missed injections between two follow-up visits was between 6 and 10 ) accounted for $18.6 \%$ and $32.4 \%$ missed up to 30 injections (4). A previous study conducted in New Zealand assessed the relationship between compliance with rhGH treatment and improved height. The results demonstrated that poor compliance significantly reduced the therapeutic effect, whereas good and excellent treatment compliance had higher growth rates and insulin-like growth factor 1 (IGF-1) levels; the growth rate was therefore negatively correlated with the number of missed injections. The findings also showed that patient compliance gradually decreased during the treatment (5). Therefore, a new rhGH injection-pegylated recombinant human growth hormone (PEG-rhGH) - emerged. Its active component is a covalent conjugate of rhGH and branched polyethylene glycol (PEG). PEG, with a high molecular weight, has low toxicity and can therefore increase the molecular weight of rhGH, prolong its half-life, and make GH produce a long-term pharmacological effect in vivo. The treatment only needs to be given once a week to achieve the therapeutic effect and reduces the risk of the injection to ensure its efficacy (6).

Subcutaneous injection of short-acting rhGH before sleep every day simulates the normal peak of human GH secretion, but PEG-rhGH only needs to be injected once a week. Whether this therapy will affect the glucose and lipid metabolisms in the human body still needs to be confirmed. In the present study, the changes in glucose and lipid indexes before and after the use of PEG-rhGH in children with GHD in the outpatient department of the hospital were recorded, the results of which are reported below. We present the following article in accordance with the STROBE reporting checklist (available at http://dx.doi. org/10.21037/apm-20-871).

\section{Methods}

\section{Subjects}

A total of 17 children with GHD who were treated in the hospital between February 2015 and November 2018 were enrolled in the study. The study was conducted in accordance with the Declaration of Helsinki (as revised in 2013). The study was approved by the Ethics Committee of Union Hospital, Tongji Medical College, Huazhong University of Science and Technology and informed consent was taken from all the patients. We declared that materials described in the manuscript, including all relevant raw data, will be freely available to any scientist wishing to use them for non-commercial purposes, without breaching participant confidentiality.

The inclusion criteria were patients with a definite diagnosis of GHD, patients with a height lower than the third percentile-or two standard deviations - of the growth curve for their age and gender, patients with a bone age that fell behind by more than a year, patients with absent adolescent development, patients with a GH peak value after $\mathrm{GH}$ provocation tests with two drugs of less than $10 \mu \mathrm{g} / \mathrm{L}$, patients with no contraindication of PEG-rhGH, and patients with complete clinical data. The blood lipid and blood glucose levels of all patients were measured.

\section{Research methods}

The selected children were treated with PEG-rhGH (trade name Juyi' Erchun) via subcutaneous injection once a week before sleep. The doses given were 0.2 or $0.15 \mathrm{mg} /(\mathrm{kg}$.week). The injection sites included the upper arm, the front of the 
thigh, and the periumbilical area of the abdominal wall. The treatment lasted for over 3 months. Follow-ups were conducted every 3 months after treatment to detect the metabolic indexes of the children's blood glucose and blood lipids. Growth and development indexes, thyroid function, and other indexes were also detected regularly.

\section{Observation indexes}

Before the treatment and every three months thereafter, the glucose and lipid metabolism indexes of each child, including fasting blood glucose, glycosylated hemoglobin, fasting insulin, total cholesterol, triglycerides, high-density lipoprotein (HDL), and low-density lipoprotein (LDL), were measured. The total detection time was 3-30 months.

The detection methods used were:

* Fasting blood glucose: hexokinase method;

* Glycosylated hemoglobin: high-performance liquid chromatography;

* Fasting insulin: chemiluminescence;

* Total cholesterol: oxidase method;

* Triglycerides: glycerophosphate oxidase method;

* HDL: chemical modification of enzymes;

* LDL: selective melt method.

\section{Statistical analysis}

Data were statistically analyzed using SPSS 19.0. Glycolipid metabolism indexes were normally distributed and expressed as mean \pm standard deviation. Data before and after the treatment were compared using a paired sample $t$-test. $\mathrm{P}<0.05$ was considered statistically significant.

\section{Results}

\section{General patient data}

Of the 17 children included in this study, 9 were male and 8 were female. The median age was 7 (range, 4-10 years). The children's gender, age, height (before and after treatment), dosage, treatment time, and monthly growth are presented in Table 1.

\section{Blood lipid and blood glucose indexes after treatment}

After administering the treatment, there were no significant differences found in fasting blood glucose, glycosylated hemoglobin, fasting insulin, total cholesterol, triglycerides,
HDL, and LDL when compared with measurements taken before treatment $(\mathrm{P}>0.05)$ (Table 2).

\section{Discussion}

Short stature is the most prominent clinical manifestation of GHD and the main reason for visits to the doctor about the condition. The damage caused by short stature cannot be underestimated: it causes both physical differences and psychological trauma, which itself may lead to other clinical manifestations, such as introverted personality, emotional instability, and severe physical and mental diseases (e.g., learning disabilities, social barriers, depression, and autism). It can, therefore, affect a child's quality of life in adulthood (7-9). As such, recovering a child's final height is vital for ameliorating the psychological impacts of GHD and promoting positive growth. At present, the treatment that can be implemented to reach this goal includes exogenous rhGH replacement therapy. The new PEG-rhGH, however, can prolong the half-life of rhGH, meaning the $\mathrm{GH}$ has a long-term pharmacological effect in the body. Further, this treatment only needs to be administered once a week to achieve the therapeutic effect, so the risk of injection can be reduced and the efficacy can be ensured (6).

$\mathrm{GH}$ can promote the growth of a patient's bones directly: it promotes IGF-1 synthesis by acting on the liver growth hormone receptor, which encourages bone growth. IGF-1 can also inhibit the release of pituitary $\mathrm{GH}$ via negative feedback. Serum IGF-1 concentration and serum growth hormone levels are roughly balanced within 24 hours. Therefore, GH itself has the physiological function of regulating glucose and lipid metabolism, an effect that is mainly achieved through the action of IGF-1. IGF-1 is a polypeptide, similar to insulin in structure and function, that can promote cell proliferation and growth and antagonize cell apoptosis. GH can activate insulinsensitive lipase, promote fat decomposition, enhance fatty acid oxidation, provide energy, and reduce the fat content of tissues, especially in the limbs. It can also inhibit the uptake and utilization of glucose in skeletal muscles and adipose tissue, reduce the consumption of glucose, and increase the level of blood glucose (10).

There is no definite theory about lipid metabolism in children with GHD. One previous study found that the blood lipid levels of children with GHD was the same as those of children without GHD (11), whereas another study found that the blood lipid levels of children with GHD were significantly higher than those of a control group (12). 
Table 1 Basic information growth hormone deficiency (GHD) children

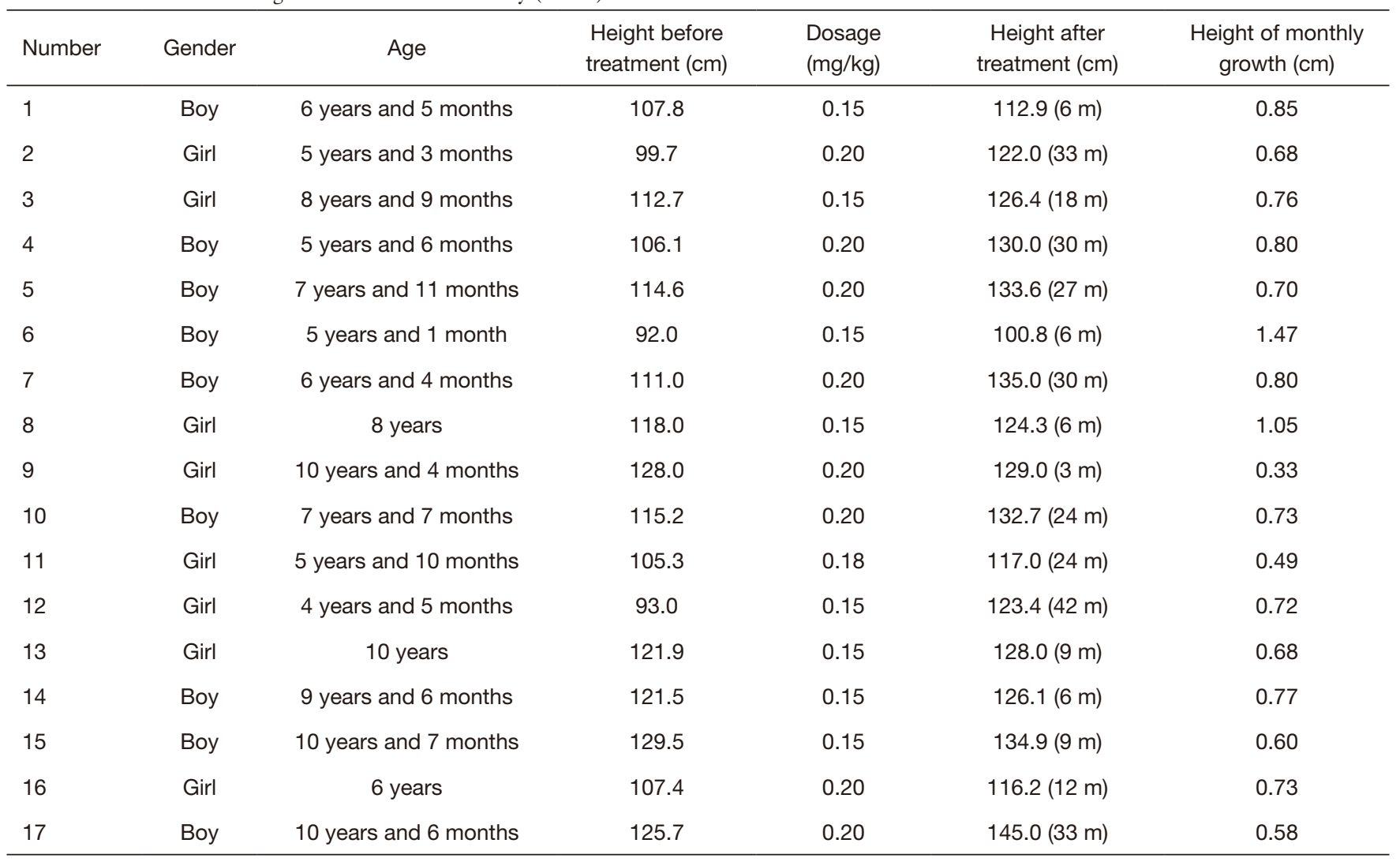

$\mathrm{m}$ indicates total months of treatment at end of treatment.

However, whether there was an abnormality or not, the blood lipid levels of the children were decreased to different degrees after administering the rhGH treatment $(13,14)$. In the present study, after only 21 months of treatment, the children's LDL levels had changed from the levels observed before the treatment $(\mathrm{P}=0.045)$, and there was no significant change in the blood lipids before and after the treatment $(\mathrm{P}>0.05)$. This may be related to the small number of patients in this study.

RhGH regulates glucose metabolism through three insulin-sensitive organs: the liver, adipose tissue, and muscle. It can increase blood glucose by activating the glucosefatty acid cycle to increase unesterified fatty acids, thereby inhibiting the oxidation of glucose in the peripheral tissues. Furthermore, rhGH treatment reduces the sensitivity of the liver tissue to insulin and accordingly increases the glycogen output of the liver and increases blood glucose (15). Although rhGH can reduce a patient's sensitivity to insulin, this change is reversible: it can return to a normal level after stopping the treatment and has no significant effect on the patient's blood glucose level. Sensitivity to insulin often occurs in children with GHD and easily develops into fasting hypoglycemia (16). In severe patients, it can lead to brain damage caused by recurrent hypoglycemia. After rhGH treatment, the symptoms of hypoglycemia and the decrease in fasting blood glucose are improved: the present study revealed that there was no significant change in blood glucose after PEG-rhGH treatment $(\mathrm{P}>0.05)$.

The physiological lipid-lowering effect of GH is relatively verified: it can induce hepatocytes and myocytes to produce GH mediators and can also directly activate the target cells to produce physiological effects. The result is that it can promote fat decomposition, increase unesterified fatty acids and triglycerides, reduce total cholesterol and low-density lipoprotein cholesterol (LDL-C), and can increase lipoprotein in a short time. Adult patients with GHD often experience an increase in the arteriosclerosis index due to abnormal lipid metabolism, which increases the risk of cardiovascular disease (17). Reasonable rhGH treatment can improve the disorder of lipid metabolism, 
Table 2 Changes of growth hormone deficiency (GHD) indicators in different treatment periods

\begin{tabular}{lccccccccccc}
\hline & \multicolumn{10}{c}{ Changes } \\
\cline { 2 - 11 } Index & $\begin{array}{c}\text { Before } \\
\text { treatment } \\
(n=17)\end{array}$ & $\begin{array}{c}3 \text { months } \\
(n=17)\end{array}$ & $\begin{array}{c}6 \text { months } \\
(n=13)\end{array}$ & $\begin{array}{c}12 \text { months } \\
(n=8)\end{array}$ & $\begin{array}{c}15 \text { months } \\
(n=8)\end{array}$ & $\begin{array}{c}18 \text { months } \\
(n=8)\end{array}$ & $\begin{array}{c}21 \text { months } \\
(n=8)\end{array}$ & $\begin{array}{c}24 \text { months } \\
(n=7)\end{array}$ & $\begin{array}{c}27 \text { months } \\
(n=7)\end{array}$ & $\begin{array}{c}30 \text { months } \\
(n=5)\end{array}$ \\
\hline FPG & $4.73 \pm 0.51$ & $4.70 \pm 0.42$ & $4.80 \pm 0.40$ & $4.51 \pm 0.41$ & $4.91 \pm 0.27$ & $4.81 \pm 0.40$ & $4.88 \pm 0.50$ & $4.60 \pm 0.58$ & $4.70 \pm 0.43$ & $4.70 \pm 0.24$ \\
HBA1C & $5.33 \pm 0.33$ & $5.31 \pm 0.30$ & $5.18 \pm 0.35$ & $5.29 \pm 0.31$ & $5.23 \pm 0.28$ & $5.29 \pm 0.37$ & $5.43 \pm 0.35$ & $5.34 \pm 0.26$ & $5.33 \pm 0.42$ & $5.42 \pm 0.37$ \\
INS1 & $2.11 \pm 1.59$ & $2.53 \pm 1.62$ & $3.30 \pm 2.16$ & $4.09 \pm 3.74$ & $5.06 \pm 4.49$ & $5.13 \pm 3.11$ & $6.77 \pm 3.63$ & $5.12 \pm 4.51$ & $4.34 \pm 2.59$ & $8.07 \pm 2.72$ \\
TC & $3.98 \pm 0.62$ & $3.95 \pm 0.81$ & $3.96 \pm 0.53$ & $4.41 \pm 0.69$ & $4.20 \pm 0.96$ & $4.12 \pm 0.76$ & $3.68 \pm 0.53$ & $3.79 \pm 0.81$ & $3.97 \pm 0.63$ & $3.84 \pm 0.85$ \\
TG & $0.68 \pm 0.19$ & $0.75 \pm 0.20$ & $0.75 \pm 0.29$ & $0.72 \pm 0.16$ & $0.73 \pm 0.22$ & $0.65 \pm 0.12$ & $0.60 \pm 0.12$ & $0.70 \pm 0.14$ & $0.74 \pm 0.25$ & $0.67 \pm 0.27$ \\
HDL & $1.58 \pm 0.33$ & $1.59 \pm 0.29$ & $1.61 \pm 0.38$ & $1.55 \pm 0.19$ & $1.48 \pm 0.32$ & $1.46 \pm 0.24$ & $1.38 \pm 0.24$ & $1.40 \pm 0.20$ & $1.44 \pm 0.15$ & $1.34 \pm 0.16$ \\
LDL & $2.09 \pm 0.56$ & $1.96 \pm 0.54$ & $1.97 \pm 0.43$ & $2.45 \pm 0.62$ & $2.32 \pm 0.81$ & $2.29 \pm 0.66$ & $2.01 \pm 0.49 *$ & $1.59 \pm 0.84$ & $2.21 \pm 0.76$ & $2.2 \pm 0.75$ \\
\hline
\end{tabular}

FPG, fasting blood glucose; HBA1C, glycosylated hemoglobin; INS1, fasting insulin; TC, total cholesterol; TG, triglyceride; HDL, high-density lipoprotein; LDL, low-density lipoprotein. ${ }^{*} \mathrm{P}=0.045$, the remaining unmarked $\mathrm{P}$ values $>0.05$.

reduce the arteriosclerosis index, decrease the mortality rate and the risk of cardiovascular disease, and improve a patient's quality of life $(18,19)$.

The limitations of the present study were such that the sample size was very small, so the clinical significance of this study is limited and it is at high risk of false-negative findings. There is also little clinical significance for the follow-up data because few cases completed the follow up.

\section{Conclusions}

This study was a retrospective analysis, and no long-term clinical follow-up analysis was performed. The sample size was small and the course of treatment was between 3 months and 2.5 years. However, its findings suggest that PEG-rhGH has no significant effect on glucose and lipid metabolism in children with GHD. The influence of medications on blood glucose and blood lipid levels was affected by medication time and dosage. The study's findings also suggest that children with GHD need longterm or even life-long treatment. Overall, the treatment's effect on the metabolism needs further study and discussion to provide a scientific basis for rational clinical drug use.

\section{Acknowledgments}

We are particularly grateful to all the people who have given us help on our article.

Funding: None.

\section{Footnote}

Reporting Checklist: The authors have completed the STROBE reporting checklist. Available at http://dx.doi. org/10.21037/apm-20-871

Data Sharing Statement: http://dx.doi.org/10.21037/apm20-871

Conflicts of Interest: All authors have completed the ICMJE uniform disclosure form (available at http://dx.doi. org/10.21037/apm-20-871). The authors have no conflicts of interest to declare.

Ethical Statement: The authors are accountable for all aspects of the work in ensuring that questions related to the accuracy or integrity of any part of the work are appropriately investigated and resolved. The study was conducted in accordance with the Declaration of Helsinki (as revised in 2013). The study was approved by the Ethics Committee of Union Hospital, Tongji Medical College, Huazhong University of Science and Technology and informed consent was taken from all the patients.

Open Access Statement: This is an Open Access article distributed in accordance with the Creative Commons Attribution-NonCommercial-NoDerivs 4.0 International License (CC BY-NC-ND 4.0), which permits the noncommercial replication and distribution of the article with the strict proviso that no changes or edits are made and the 
original work is properly cited (including links to both the formal publication through the relevant DOI and the license). See: https://creativecommons.org/licenses/by-nc-nd/4.0/.

\section{References}

1. Chinoy A, Murray PG. Diagnosis of growth hormone deficiency in the paediatric and transitional age. Best Pract Res Clin Endocrinol Metab 2016;30:737-47.

2. Bohdanowicz-Pawlak A, Szymczak J, Bladowska J, et al. Risk factors of cardiovascular disease in GH-deficient adults with hypopituitarism: a preliminary report. Med Sci Monit 2006;12:CR75-80.

3. Barreto-Filho JA, Alcantara MR, Salvatori R, et al. Familial isolated growth hormone deficiency is associated with increased systolic blood pressure, central obesity, and dyslipidemia. J Clin Endocrinol Metab 2002;87:2018-23.

4. Smith SL, Hindmarsh PC, Brook CG. Compliance with growth hormone treatment--are they getting it? Arch Dis Child 1993;68:91-3.

5. Cutfield WS, Derraik JG, Gunn AJ, et al. Non-compliance with growth hormone treatment in children is common and impairs linear growth. PLoS One 2011;6:e16223.

6. Luo X, Hou L, Liang L, et al. Long-acting PEGylated recombinant human growth hormone (Jintrolong) for children with growth hormone deficiency: phase II and phase III multicenter, randomized studies. Eur J Endocrinol 2017;177:195-205.

7. Kao KT, Stargatt R, Zacharin M. Adult Quality of Life and Psychosocial Outcomes of Childhood Onset Hypopituitarism. Horm Res Paediatr 2015;84:94-101.

8. Chaplin JE, Kristrom B, Jonsson B, et al. Improvements in behaviour and self-esteem following growth hormone treatment in short prepubertal children. Horm Res Paediatr 2011;75:291-303.

9. Wheeler PG, Bresnahan K, Shephard BA, et al. Short stature and functional impairment: a systematic review. Arch Pediatr Adolesc Med 2004;158:236-43.

10. Weber MM, Biller BM, Pedersen BT, et al. The effect

Cite this article as: Wang $\mathrm{C}$, Huang $\mathrm{H}$, Zhao C, Zhao J, Xiong R, Jin R, Bai Y. The impact of pegylated recombinant human growth hormone replacement therapy on glucose and lipid metabolism in children with growth hormone deficiency. Ann Palliat Med 2021;10(2):1809-1814. doi: 10.21037/apm-20-871 of growth hormone $(\mathrm{GH})$ replacement on blood glucose homeostasis in adult nondiabetic patients with GH deficiency: real-life data from the NordiNet ${ }^{\circledR}$ International Outcome Study. Clin Endocrinol (Oxf) 2017;86:192-8.

11. Esposito V, Di Biase S, Lettiero T, et al. Serum homocysteine concentrations in children with growth hormone $(\mathrm{GH})$ deficiency before and after 12 months $\mathrm{GH}$ replacement. Clin Endocrinol (Oxf) 2004;61:607-11.

12. Gleeson HK, Souza AH, Gill MS, et al. Lipid profiles in untreated severe congenital isolated growth hormone deficiency through the lifespan. Clin Endocrinol (Oxf) 2002;57:89-95.

13. Kubo T, Furujo M, Takahashi K, et al. Effects of Growth Hormone Treatment on Lipid Profiles. Indian J Pediatr 2018;85:261-5.

14. Ciresi A, Amato MC, Criscimanna A, et al. Metabolic parameters and adipokine profile during $\mathrm{GH}$ replacement therapy in children with GH deficiency. Eur J Endocrinol 2007;156:353-360.

15. Dalmolin C, Almeida DV, Figueiredo MA, et al. Expression profile of glucose transport-related genes under chronic and acute exposure to growth hormone in zebrafish. Comp Biochem Physiol A Mol Integr Physiol 2018;221:1-6.

16. Jørgensen JO, Krag M, Jessen N, et al. Growth hormone and glucose homeostasis. Horm Res 2004;62 Suppl 3:51-5.

17. Jørgensen JO, Møller L, Krag M, et al. Effects of growth hormone on glucose and fat metabolism in human subjects. Endocrinol Metab Clin North Am 2007;36:75-87.

18. Gazzaruso C, Gola M, Karamouzis I, et al. Cardiovascular risk in adult patients with growth hormone $(\mathrm{GH})$ deficiency and following substitution with $\mathrm{GH}$--an update. J Clin Endocrinol Metab 2014;99:18-29.

19. Beauregard C, Utz AL, Schaub AE, et al. Growth hormone decreases visceral fat and improves cardiovascular risk markers in women with hypopituitarism: a randomized, placebo-controlled study. J Clin Endocrinol Metab 2008;93:2063-71. 